\title{
Developing of teaching experiment system for dynamically observing and measuring to cutting process
}

\author{
Zhang Yue ${ }^{1, a *}$, Zuo Lina ${ }^{2}$, Han $\mathrm{Li}^{1}$, Ma Yu-qiang ${ }^{3}$ \\ ${ }^{1}$ School of Mechanical Engineering, Shenyang Univrsity of Technology, Shenyang 110870, China \\ ${ }^{2}$ Shenyang Northeast Pharmaceutical equipment manufacturing and installation Co., Ltd., \\ Shenyang 110027, China \\ ${ }^{3}$ Shenyang YIXIN Science and Technology Development Company Ltd., Shenyang 110027, China \\ azhy@sut.edu.cn
}

\begin{abstract}
Keywords: metal cutting; cutting layer; dynamically observing; teaching experiment; transducer.
Abstract. A teaching experiment was developed to observing and measuring to cutting process, to improve the teaching performance of the "fundamentals of mechanical manufacturing technology" course. The experiment is carried out on a column milling machine tool; the cutting tool is fixed on the overarm; the board type workpiece is fixed on the worktable. Under the planning fashion at low cutting speed, a CCD microcamera was used to screen from tool orthogonal plane and the orthogonal cutting process can be observed on the display. A transducer was applied to change the speed of worktable with stepless regulation, and the methods of machine tool circuit rebuilding and transducer using were mentioned. So did the buildup of CCD microcamera. The intuitionistic observing to cutting process can be obtained in the experiment, and it can be measuring for rake angle, clearance angle, shear angle, cutting layer and chip thickness, and then the deformation coefficient can be calculated. To the experiment of dynamically observing and measuring to cutting process, the operation is simpleness; the teaching performance is evident; the students feedback is preferably; and the extend value is significant.
\end{abstract}

\section{Introduction}

Under the background of rapidly economic development, the institution of higher learning, as a place to train talents, must stand on the new straining point; establish the strategy and goals to cultivate talents which adapt to the social development; construct the platform which aids to the training of creative talents and the development of higher education; cultivate and raise the students' practical ability and creative capacity; then translate them into innovative and enterprising spirit, which could make the students cope with the severe employment situation. In the educational reform, the teachers bring the modern technology to the orthodox teaching. That make the teachers to give more wonderful lessons and to improve their professional quality. Finally that will make the students master the professional knowledge and enhance their synthetical abilities. ${ }^{[1-4]}$

The courses, such as, "the fundamentals of the mechanical manufacturing technology" or "the principal of mental-cutting" are the main courses which are specialized in the machine in the most of the engineering colleges. Metal-cutting process is the essential course mentioned above. Metal-cutting process we can briefly describe that the metal of the cutting layers is jostled by the front side of the cutters, and then is produced the plastic deformation which is mainly caused by shearing and slipping deformation. That is the process of cutting into the metal filings. ${ }^{[4-8]}$

Traditionally, to observe and measure the forming process of cutting the metal filings, we needed to use the device which made the cutting tool rapidly drop down, to get the cutting roots and make the metallographic sample which was observed under the microscope. This method could finish researching on cutting process, but we could only gain the static photographs, further more the experimental procedures were time-consuming. Thus, this method is hard to be satisfied with present teaching requirements. It was more difficult for the students to understand it.

For ease of operation and comprehension, and the students can directly see the process, we designed teaching experiment system for dynamically observing and measuring to cutting process. The 
experiments was carried out in X62W milling machine, adopted the transducer to convert the speed of motor to make the cutting speed fit the requirements of observing and measuring; meanwhile, used some equipment's, such as, CCD micro video camera, video capture cards, and a computer to collect video signal to make the students enable to dynamically observe the process of the cutting formation.

\section{Overall plan}

The equipments and instruments which are needed in the teaching experiment system of the cutting layers deformation for dynamically observing: X62W milling machine, a transducer, CCD micro video camera, video capture cards and a computer, etc. Figure 1 shows the teaching experiment system of the cutting process for dynamically observing and measuring. CCD micro video camera and the cutting tools are both installed on the hanger. We adjust the fine tuning of CCD micro video camera to focus it on the point of the cutting tool. After manually checking the cutting tool, and giving the cutting depth, we started up the transducer and the feed motor to make the workbench move towards the vertical surface inward the direction In figure 1. At the moment, as being shown in figure 1, it can be seen the deformation process of the cutting layers on the monitor.

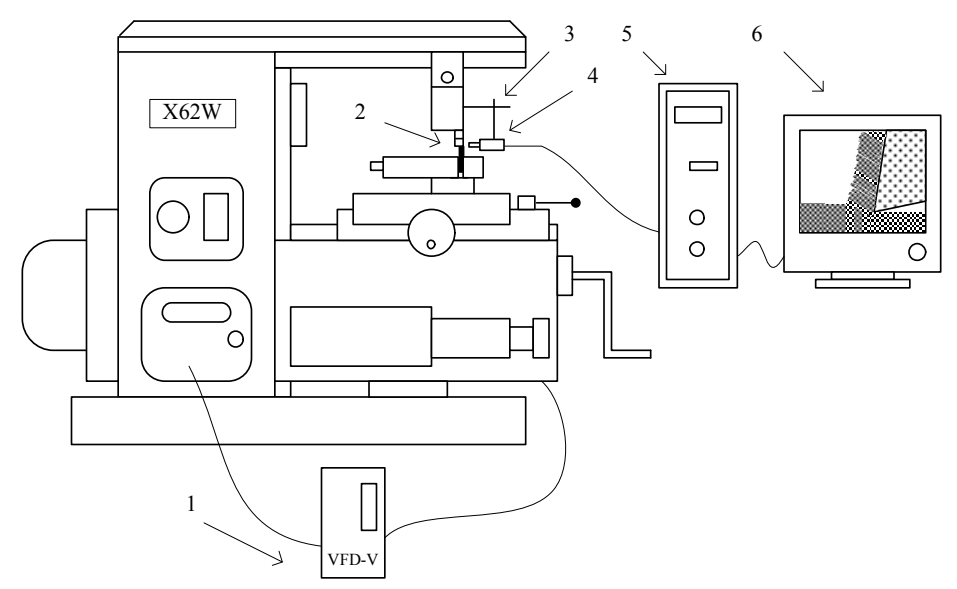

1. a transducer 2 . a cutting tool and a workpiece 3 . CCD fine tuner 4. CCD micro video camera 5 a computer 6 a monitor

Figure 1 Teaching experiment system for dynamically observing and measuring to cutting process

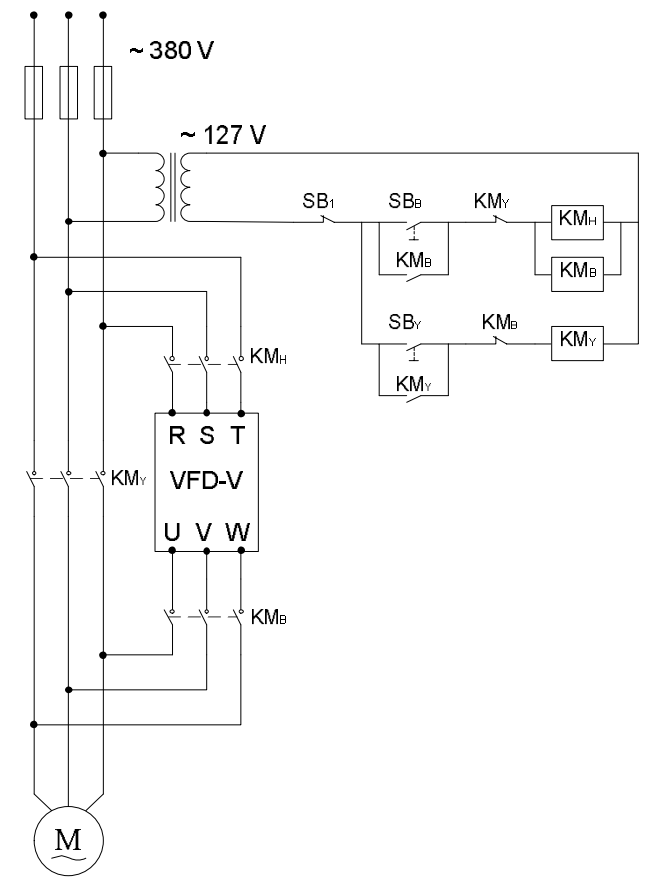

Figure 2. The circuit diagram for electrical deformation of a lathe

\section{The electrical renovation of the lathes}

It is planned to have the experiment on the model X62W milling machine. But it was too speedy for this experiment that the least laterally moving speed of the workbench on the milling machine was $23.5 \mathrm{~mm} / \mathrm{min}$. For being satisfied with observing requirements, we must reduce the moving speed of the workbench. Actually, the speed was only $5-10 \mathrm{~mm} / \mathrm{min}$ when we had the experiment. So we adopted the transducer to reduce the speed of the workbench by reducing the motor speed. It is necessary to remold the electrical circuit of the lathe. After using the transducer, here is also derivate the formula of calculating table running speed

No-rate speed adjustment of feed motor. (1) In consideration of practical needs, after adapted, it requires: no replacement for motor. (2) Transducer can access and exit at any time. The operating for switching access and exit is convenient. We won't change the custom of operations after we access the transducer; it means that after access the transducer. It will only take effects as speed governing. The 
operation such as working table movement of commuting direction will still finish by original lathe handle. Basing on requirements mentioned above, we designed electrical adaptation of the lathe as shown in Figure 2. Built on the original foundation, we added model VFD-V transducer, buttons, alternating current relay as well as kit. The electrical equipment KMB and KMY's interlock is to avoid the connection reduce the working table's speed of transducer output lead and $380 \mathrm{~V}$ electrical power which will cause the damage of transducer.

Transducer. According to the practical necessity, we adopted a transducer to decrease the speed of the motor, thus, the cutting speed reduced. After analyzing the advantages and disadvantages, we choose the model of the transducer as VFDD15V43A. Because the experiment required reduction of the motor rpm (revolutions per minute) only, so here some parameters are adjusted. After adjustment, the strait of the transducer and stop is controlled by SB. The operating frequency is given by resistance $\mathrm{R}$. Its range is $0-50 \mathrm{~Hz}$.

CCD micro-video camera system. CCD is an abbreviation of Charge Couple Device. CCD image sensor is the hardcore of CCD video camera. Scenery in the spot was taken by a camera lens and then CCD image sensor in the video camera got its imaging which was output by CCD image sensor and formed its electrical signal, and then, which was speedily manipulated by the circuit and collective cards of the video inside micro video camera and the image of the scenery was output in the screen of the computer. The lens of the microcamera, which has an object glass of a microscope, is connected with a bushing and the camera. The bushing is fixed on the fixture of the adjustment. The outputting of an analog video and collective cards of the video frequency are connected with transmission lines. This system of the camera is completely satisfied with the requirements of the experiment. It can output the video, the procedure out of shape of the cutting layer, onto the screen, and in the computer for use. The scope of the video became smaller because we adopted microscope lens. We had to design the device of the fine-tuning position in the CCD micro video camera to carry out adjusting three directions of $\mathrm{x}$, $\mathrm{y}, \mathrm{z}$. for taking the clear picture which was aiming at the cutting area.

\section{The procedure and the result of the experiment}

We planned the contents of the experiments according to the requirements of the course and the practical condition of the experimental systems. For the convenient observation in the experiment, we adopted automatic right-angle-cutting mode, which is similar to cutting with the wide blade of a plane. Meanwhile, on the side of the cutting tool and the workpiece, it is videoed with CCD micro-video camera. The experiment is made with high-speed steel cutting tools and the workpiece was made of aluminum and cast iron. In this way, the students can observe the cutting process of plastic material and fragile material, and the characteristics of cutting the pieces. Figure 3 shows the theoretical diagram of the cutting process.

In the experiment, it must be paid attention to that the sides of the cutting tools and the sides of the workpieces, which are videoed, should be in the vertical plane, or the videoed picture of the cutting tool is in focus, but the videoed picture of the workpiece isn't very clear, and vice versa. Whenever we video, we should clean the front surface of the cutting tool to prevent the residues affecting our observation. Figure 4 shows the picture of the cutting process.

\section{Conclusions}

Adopting the transducer has made the running speed of the cutting tool on the lathe further reduced. Through using the CCD micro-video camera system, we have achieved to observe dynamically the deformation of the cutting layers.

The experiment for dynamically observing of cutting layer deformation has been included in the undergraduate course in our university. The students can visually see the deformation of the cutting layers and the process which the metal filings were cut away. That gave the students an insight into the 
cutting-metal process. This experiment can be arranged before the class teaching. In this way, the students will have the perceptual knowledge at first, and then they will obtain/ripen into the rational knowledge after the class teaching. In a word, the dynamically observing experiment about the deformation of cutting layers has so many features, such as, great flexibility, simple operation, small investment and obvious teaching effect, etc. It is worth popularizing.

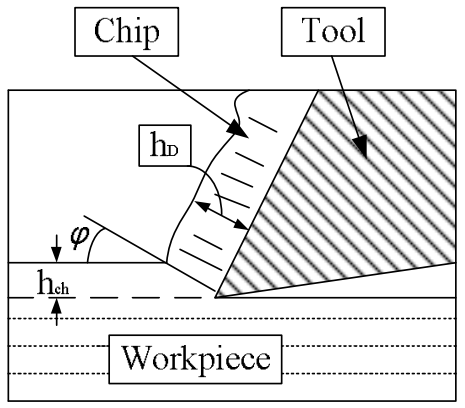

Figure 3 The theoretical diagram of the cutting process

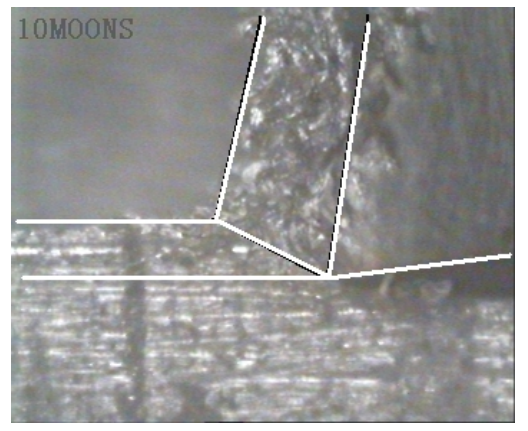

Figure 4 The picture of the cutting process

\section{Acknowledgements}

This research reported in the paper is financially supported by Foundation of Liaoning Province Education Department (L2012042), Doctoral Research Foundations of Liaoning Province (20121058) and Shenyang University of Technology (521101302), Young Backbone Teacher Foundation of Shenyang University of Technology (004436521). These supports are greatly acknowledged.

\section{References}

[1] Wang Lei, Zheng Yaliang. The Training strategies for the innovating asset in the higher education. In the Journal of Shenyang university of technology,2009(4): 381-384

[2] Deng Biao, Zhuang Na. College students' professionally developmental education under the situation of the financial crisis. In the Journal of Shenyang University of Technology, 2009(3): 282-284

[3] Ma Jin, Tang Gongzhi. Talking about the teachers' more professionalism from the viewpoint on improving the teaching quality. In the Journal of Shenyang University of Technology,2009(2): $185-188$

[4] Qu Xiangrong. Practice and thinking of giving competitively observing classes. In the Journal of Shenyang University of Technology, 2008(2): 176-179

[5] Yu Junyi, Zou Yi.The technical basics of the mechanical manufacturing. Beijing: Mechanical Industry Press , 2004.5.

[6] Zhang Shichang, Li Dan, Gao Hang. The technical basics of the mechanical manufacturing. Beijing: Higher Education Press , 2001.

[7] Han Rongdi, Zhou Ming, Sun Yujie. The principle of cutting metal and the Cutting Tool. Harbin: Harbin Industrial University Press, 2004.

[8] Zeng Yi, Wang Xiaoliang, Wu Hao. Design and Maintenance for the Control System of Frequency Conversion. Ji Nan: Shandong Science and Technology Press, 2002. 